\title{
Attitudes of younger and older adults towards kidney diseases in Greece
}

\author{
Vaitsa Giannouli, ${ }^{1}$ Nikolaos Syrmos ${ }^{2}$ \\ ${ }^{1}$ Bulgarian Academy of Sciences, Sofia, Bulgaria; ${ }^{2}$ Aristotle University of Thessaloniki, Greece
}

\section{Letter to the Editor}

Patients with different types of kidney diseases exist worldwide. Given the fact that chronic kidney disease is one of the most prevalent kidney problems (Atkins, 2005; World Kidney Day, 2019; Glassock \& Winearls, 2008), and knowledge on kidney diseases is progressing through clinical and experimental medical research, still little is known about the attitudes that the public has on health problems related to the kidney. Thoughts and feelings of the general public have been extensively examined mainly for psychiatric diseases (Angermeyer \& Dietrich, 2006; Schomerus et al., 2012), but attitudes and possible misconceptions for other types of physical diseases are still not examined (Giannouli \& Syrmos, 2017). The aim of this study is to fill in the blank by assessing the attitudes towards kidney diseases in healthy adults from Greece.

204 participants (97 men and 197 women, with ages ranging from 18-75 years) from different geographical areas of Greece, replied voluntarily to a new questionnaire related to their attitudes towards kidney diseases. The questionnaire consisted of open questions and questions in the form of a 5-point Likert scale, with statements ranging from 'strongly agree' to 'strongly disagree'. Participants were categorized by age into young adults (aged 1835 years; $n=69$ ), middle-aged adults (aged 36-55 years, $n=71$ ), and older adults (aged older than 55 years, $n=64$ ). Participants were also categorized according to their educational level and their cur-

Correspondence: Vaitsa Giannouli, Institute of Neurobiology, Bulgarian Academy of Sciences, Acad. G. Bonchev str., bl. 23, 1113 Sofia, Bulgaria.

E-mail: giannouliv@hotmail.com

Key words: Attitudes, health, kidney disease.

Contributions: VG and NS jointly initiated the study and planned the research design.VG and NS collected the data. VG was the primary author of the manuscript, and VG was engaged in data analysis. All the authors critically read and revised the final version of the manuscript.

Conflict of interest: The authors declare no potential conflict of interest.

Funding: None

Received for publication: 11 April 2019.

Accepted for publication: 27 November 2019.

This work is licensed under a Creative Commons AttributionNonCommercial 4.0 International License (CC BY-NC 4.0).

CC Copyright: the Author(s), 2019

Licensee PAGEPress, Italy

Health Psychology Research 2019; 7:8230

doi:10.4081/hpr.2019.8230 rent occupation as: unemployed (58), university students (24), professionals (65), and retired laypeople with different occupations (62). The majority of the participants (179) were healthy at the time of the research, and the rest were patients suffering from chronic diseases other than kidney diseases (25).

Results showed that when participants were asked to mention explicitly what kind of kidney disease they know, they were unable to write more than two types of kidney diseases (82\%) and the main type was chronic kidney disease (80\%). When asked if they are afraid of a specific type of kidney disease, they responded that they are more afraid/scared of a specific diagnosis of kidney disease: chronic kidney disease $(77 \%)$ with the characteristic of renal failure $(72 \%)$, but this is not their number one disease fear. When asked to name any physical disease that they fear the most, the majority indicated cardiovascular disease (86\%). Although they claim that they do not know in detail the causes - risk factors (67\%), the mechanism of chronic kidney disease $(83 \%)$, and the diagnostic signs of it (88\%), they express great fear $(79 \%)$ and anxiety $(73 \%)$ for the possibility of being a patient suffering of a kidney disease themselves $(78 \%)$ or one of their family members $(72 \%)$, or one of their friends $(71 \%)$. This fear is mainly based on the physical handicap that is not only related to pain in the body $(63 \%)$, but also everyday problems in the family and social life (77\%). They believe that as with other diseases (mainly they refer to cardiovascular diseases $-85 \%$ ), there are a lot of factors that may have a relationship with kidney diseases. They mention both somatic factors such as diabetes $(74 \%)$, obesity $(72 \%)$, and generally unhealthy style of living (83\%), and psychosocial factors, such as depression (60\%) and stress (75\%), that relate according to their opinion with all types of kidney diseases. About the kidney transplant and the living donation, the majority of the participants report poor knowledge on the issue $(91 \%)$ and they also demonstrated lack of knowledge on other medical interventions for kidney problems (95\%). They expressed fear for the related financial costs $(96 \%)$, but paradoxically they responded that they were not screened for kidney disease during the last year (96\%). Finally, there were no statistically significant differences in the above, when age and health status were taken into account in the analyses, but there was a statistically significant difference on the fear towards kidney diseases when sex was used as a grouping variable, with women demonstrating greater fear $(p<0.005)$.

This research shows that there is still lack of information on what is already known on kidney diseases to the wider public in Greece and that we need a better understanding for the negative attitudes regarding kidney diseases. Awareness of the attitudes on kidney diseases in different cultural environments will not only augment the scientific knowledge for the better support of the patients, but may also influence the actions-behaviors and improve the degree of engaging in health-related activities, through educational experiences focusing on disease prevention and health promotion initiatives that will take into account the above information. 


\section{References}

Angermeyer, M.C., \& Dietrich, S. (2006). Public beliefs about and attitudes towards people with mental illness: A review of population studies. Acta Psychiatrica Scandinavica, 113(3), 163179.

Atkins, R. C. (2005). The epidemiology of chronic kidney disease. Kidney International, 67, S14-S18.

Giannouli, V., \& Syrmos, N. (2017). Exploring attitudes towards endocrine diseases in Greece. Endocrine, 55(2), 655-657.

Glassock, R. J., \& Winearls, C. (2008). An epidemic of chronic kidney disease: fact or fiction?. Nephrology Dialysis Transplantation, 23(4), 1117-1121.

Schomerus, G., Schwahn, C., Holzinger, A., Corrigan, P. W., Grabe, H. J., Carta, M. G., \& Angermeyer, M. C. (2012). Evolution of public attitudes about mental illness: A systematic review and meta-analysis. Acta Psychiatrica Scandinavica, 125(6), 440-452.

World Kidney Day. Prevalence of Chronic Kidney Disease. [Internet, cited 2019 May 19]. Available from http://www.worldkidneyday.org/faqs/chronic-kidneydisease/\#prevalence-of-ckd 